\title{
Robotic renal surgery: The future or a passing curiosity?
}

\author{
Jeff Warren, MD; ${ }^{*}$ Vitor da Silva, BMSc; ${ }^{\dagger}$ Yves Caumartin, MD; ${ }^{\neq}$Patrick P.W. Luke, MD ${ }^{* \dagger}$
}

\begin{abstract}
The development, advancement and clinical integration of robotic technology in surgery continue at a staggering pace. In no other discipline has this rapid evolution occurred to a greater degree than in urology. Although radical prostatectomy has grown to become the prototypical application for the robot, the role of the robot in renal surgery remains controversial. Herein we review the literature on robotic renal surgery. A comprehensive PubMed literature search was performed to identify all published reports relating to robotic renal surgery. All clinically related articles involving human participants were critically appraised in this review. Fifty-one clinical articles were included, encompassing robot-assisted pyeloplasty, nephrectomy, nephroureterectomy, living-donor nephrectomy and partial nephrectomy. Feasibility has been shown for each of these procedures. Robot-assisted techniques have been described for almost all renal-related procedures. However, the intersect between feasibility and necessity as it pertains to robotic renal surgery has yet to be defined. Also, the high cost of surgical robotic technology mandates critical appraisal before adoption, especially in a publicly funded health care system, such as the one present in Canada.
\end{abstract}

Can Urol Assoc J 2009;3(3):231-40

\section{Résumé}

Le développement, le perfectionnement et l'intégration en milieu clinique de la technologie robotique en contexte opératoire se poursuit à un rythme stupéfiant. Aucune autre discipline n'a vu cette évolution rapide à un niveau aussi élevé que I'urologie. Alors que la prostatectomie radicale en est devenue l'application prototype, le rôle de la robotique en chirurgie rénale demeure controversé. Dans l'article qui suit, nous passons en revue la littérature portant sur l'emploi de la robotique en chirurgie rénale. Une recherche exhaustive dans la base de données PubMed a été effectuée afin de cerner les rapports sur le sujet. Tous les rapports cliniques portant sur des sujets humains ont été évalués. Cinquante et un articles cliniques ont été inclus dans notre analyse, incluant des cas, tous assistés par robot, de pyéloplastie, de néphrectomie, de néphro-urétérectomie, de néphrectomie chez des donneurs vivants et de néphrectomie partielle. Pour chacune de ces interventions, la faisabilité a été démontrée. Des techniques assistées par robot ont été décrites pour pratiquement tous les types d'interventions rénales. Néanmoins, le point d'intersection entre faisabilité et nécessité concernant I'utilisation de la robotique reste à définir. Par ailleurs, le coût élevé de la robotique chirurgicale justifie une évaluation critique avant l'adoption de cette technologie, en particulier dans un système de santé public comme celui du Canada.

\section{Introduction}

The worldwide evolution of robotic surgery continues to advance at a staggering pace. In less than 20 years, the technology has grown exponentially from theoretical military application to daily use in operating rooms around the globe. In fact, the overwhelming success of robotic surgery with regard to invention, innovation and adaptation is an excellent example of collaboration between surgeons, industry and government. Although the first robotic device to be used clinically dates back to computed tomographyguided stereotactic neurosurgery by Kwoh and colleagues in 1988, ${ }^{1}$ the first urological application in a human was not described until Davies and colleagues ${ }^{2}$ used a modified industrial robotic arm to perform a transurethral resection of the prostate 3 years later.

The first commercial application in laparoscopy did not come until the Automated Endoscopic System for Optimal Positioning (AESOP) was approved by the US Food and Drug Administration (FDA) in 1993. ${ }^{3}$ Originally designed by the US military, the table-mounted device could precisely guide a laparoscope, and was later put into production by Computer Motion, Inc. ${ }^{4}$ Computer Motion, Inc., would later introduce the ZEUS Robotic Surgical System to the US market in 1998, just months after the unveiling of another surgical robot, the da Vinci (Intuitive Surgical, Inc.). The da Vinci Surgical System was born out of technology designed by NASA, also originally intended for use by the US military, but quickly adopted for civilian use. In 2003, Intuitive Surgical, Inc., amalgamated with Computer Motion, Inc., thereby paving the way for the clinical development of the da Vinci robot, along with its newly FDA-approved EndoWrist, to dominate surgical robotic use worldwide. ${ }^{4}$ Today, the vast majority of published literature on robot-assisted renal surgery has reported the use of the da Vinci system, and it is the only commercially 
available master-slave robotic system in production today. Furthermore, when compared with other robotic platforms, namely, AESOP and ZEUS, we have shown that the da Vinci platform is superior in terms of shorter operative time, quicker anastomotic time, flatter learning curve, as well as more intuitive technical maneuvering. ${ }^{5,6}$

Although the field of urology was not the first medical discipline to embrace robotic technology, it has adopted the technology with open arms, especially in the United States. Today, the major clinical application for the da Vinci system has been for urological procedures. However, since most of the published research and clinical experience in recent years has focused predominantly on robot-assisted radical prostatectomy, $4,7,8$ the role of robotics in renal surgery continues to be defined. With the exception of robotassisted laparoscopic pyeloplasty (RALP), the literature consists primarily of case series and reports. As such, the emphasis of this review will be on RALP. Herein we focus on the indications, techniques and surgical experiences described in the literature to date as it applies specifically to robot-assisted laparoscopic renal surgery.

\section{Methods}

A PubMed (www.pubmed.com) literature search was performed to capture all contemporary published articles (2000-2008) related to robotic renal surgery. Multiple queries were performed and all relevant English language papers were reviewed, including case reports, case series and comparative trials. Basic science and engineering-related abstracts, studies involving nonhuman subjects and percutaneous surgery papers were not critically assessed. Previously published clinical review articles and accepted abstracts for the Canadian Urological Association and American Urological Association annual meetings (2003-2008) on robotic surgery for urological application were also assessed as a means of increasing the breadth of this review.

\section{Results}

In the preliminary search, 301 articles were captured. Of these, 51 were deemed suitable for analysis. The majority of relevant papers (41) focused on robot-assisted pyeloplasty, nephrectomy, nephroureterectomy, living-donor nephrectomy or partial nephrectomy. Published reports of novel applications of renal robotic surgery and extirpative adrenal surgery were also assessed.

\section{Pyeloplasty}

Until recently, open dismembered pyeloplasty has been the gold standard treatment of adult ureteropelvic junction obstruction (UPJO) with published success rates consistently greater than $90 \%{ }^{9,10}$ However, the morbidity of a flank incision has led to the adoption of less-invasive modalities such as endopyelotomy and laparoscopic pyeloplasty. Ever since the first description by Schuessler and colleagues ${ }_{11}^{11}$ modern laparoscopic pyeloplasty series consistently demonstrate equivalent success rates to open series with improved postoperative convalescence. ${ }^{12-17}$ Unfortunately, the need for complex intracorporeal reconstruction has limited the widespread application of standard laparoscopic pyeloplasty, thereby paving the road for the potentially more facile robot-assisted approach. The da Vinci surgical robot is endowed with features that simplify intracorporeal reconstruction and suturing, effectively shortening the learning curve for residents, clinical fellows and other novice laparoscopists alike., ${ }^{5,6}$

The first clinical experience with RALP in humans was reported in 2002 by Gettman and colleagues, ${ }^{18,19}$ and provided acceptable short-term outcomes in a small number of patients. Since then, several other groups have reported similar satisfactory results as the body of literature continues to expand (Table 1). The indications for RALP are the same as standard laparoscopic or open pyeloplasty. RALP has been performed safely and effectively in patients with primary UPJO or secondary UPJO after a failed previous repair, ${ }^{28,31,33}$ as well as in both pelvic and horseshoe kidneys. ${ }^{28,31,34}$ The robotic approach can also be used to successfully manage concomitant renal stones at the time of the surgery. ${ }^{23,25,28,34}$ Contraindications to RALP are the same as standard laparoscopic pyeloplasty and include poor renal function, poor surgical candidate, uncorrected coagulopathy, abdominal wall infection and bowel obstruction.

Many techniques for RALP have been described in the literature and most are variations on the same theme. Pneumoperitoneum is achieved with a Veress needle or Hasson trocar and the initial 12-mm port is placed at the umbilicus. Most authors use this port as their primary laparoscopic port. Two additional 8-mm robotic arm ports are then placed to form an isosceles triangle with the base facing laterally (Fig. 1). Depending on surgeon preference, a 12-mm assistant port is placed in either the subxyphoid position, inferior to the camera port, or just caudal to the McBurney point on the ipsilateral side. This port can be used for suction-irrigation, retraction, introduction and removal of suture material, and placement of a double J stent. Nephroscopy and basket stone extraction can also be performed through this port as needed. Some authors, especially in the pediatric setting, use a total of only 3 ports. ${ }^{28,30,35}$ Our preferred technique is slightly different. A $12-\mathrm{mm}$ umbilical port is established for access, but is later used as an assistant 


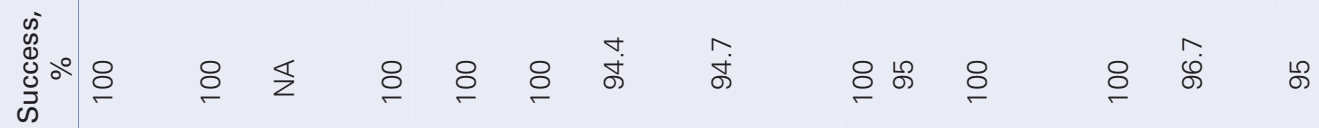

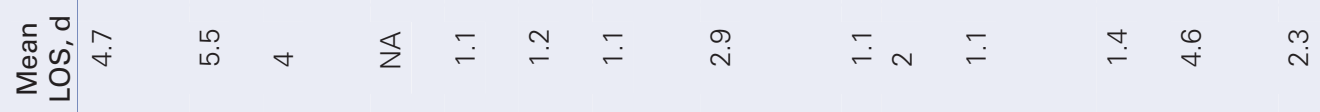

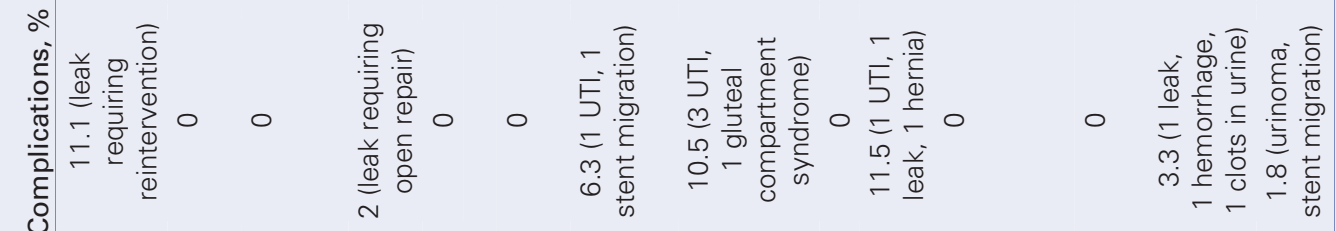

舟

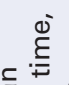

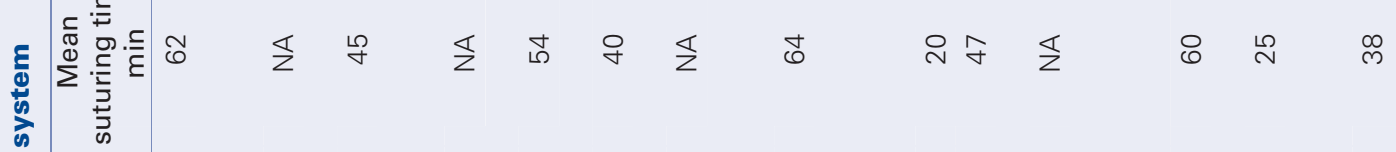

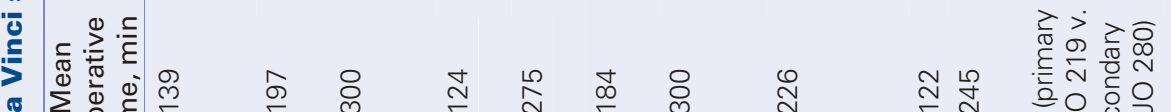

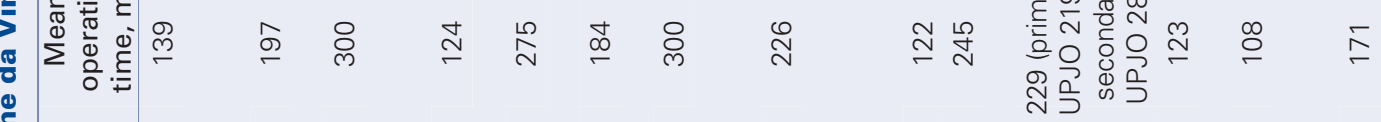
$\div \stackrel{\circ}{\circ}$

일

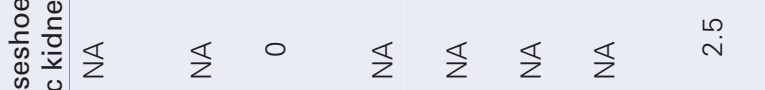

$\stackrel{\Sigma}{z}$

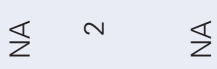

호 $\frac{0}{2}$

웅

$\frac{\pi}{0} \cdot \frac{1}{3} \frac{1}{2}$

要

긍ㅇำ

잉ำ

is

앙ㅇํ

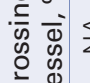

$\stackrel{\infty}{\circ}$

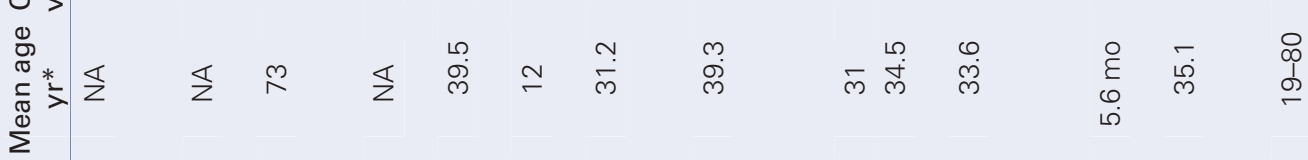

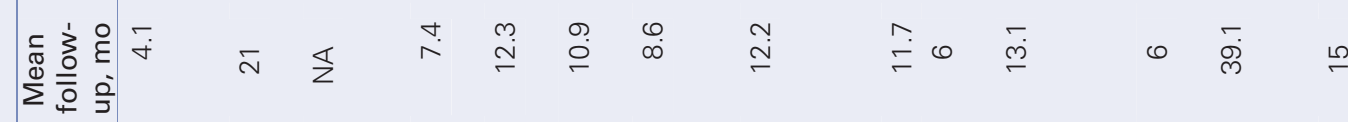

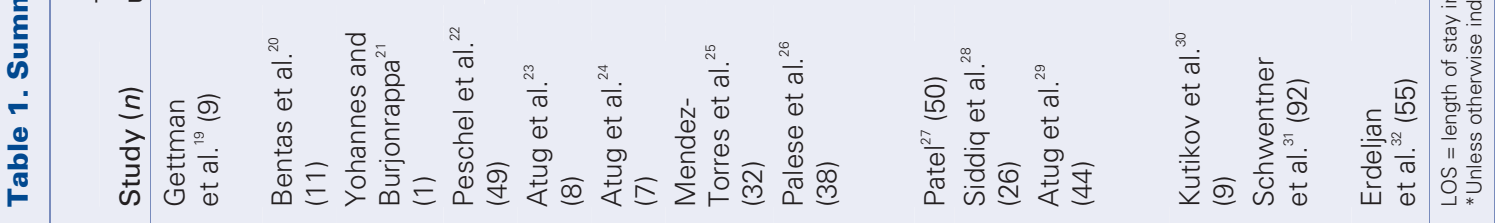


port. The laparoscope port is then established laterally in a position placed directly over the ureteropelvic junction (previously established by preoperative retrograde pyelography). We then place 2 additional 8-mm robotic arm ports to create an isosceles triangle with the base facing medially (Fig. 2). We feel this technique allows more freedom for the assistant to manoeuvre by preventing conflicts with the robot arms. The robot is then docked posteriorly to the patient (Fig. 3). At this time, all steps of traditional Anderson-Hynes dismembered pyeloplasty, Y-V plasty and Fenger-plasty can be performed. ${ }^{18,25,27,28,31} \mathrm{~A}$ dismembered technique is most commonly employed as we believe that this provides the best results in open and standard laparoscopic pyeloplasty. It also allows versatility in almost all clinical scenarios, including repair of UPJO in the presence of crossing vessels, renal calculi, large renal pelvis requiring reduction and secondary repairs. ${ }^{36}$ Some authors describe a hybrid approach whereby the initial dissection of the colon, renal pelvis

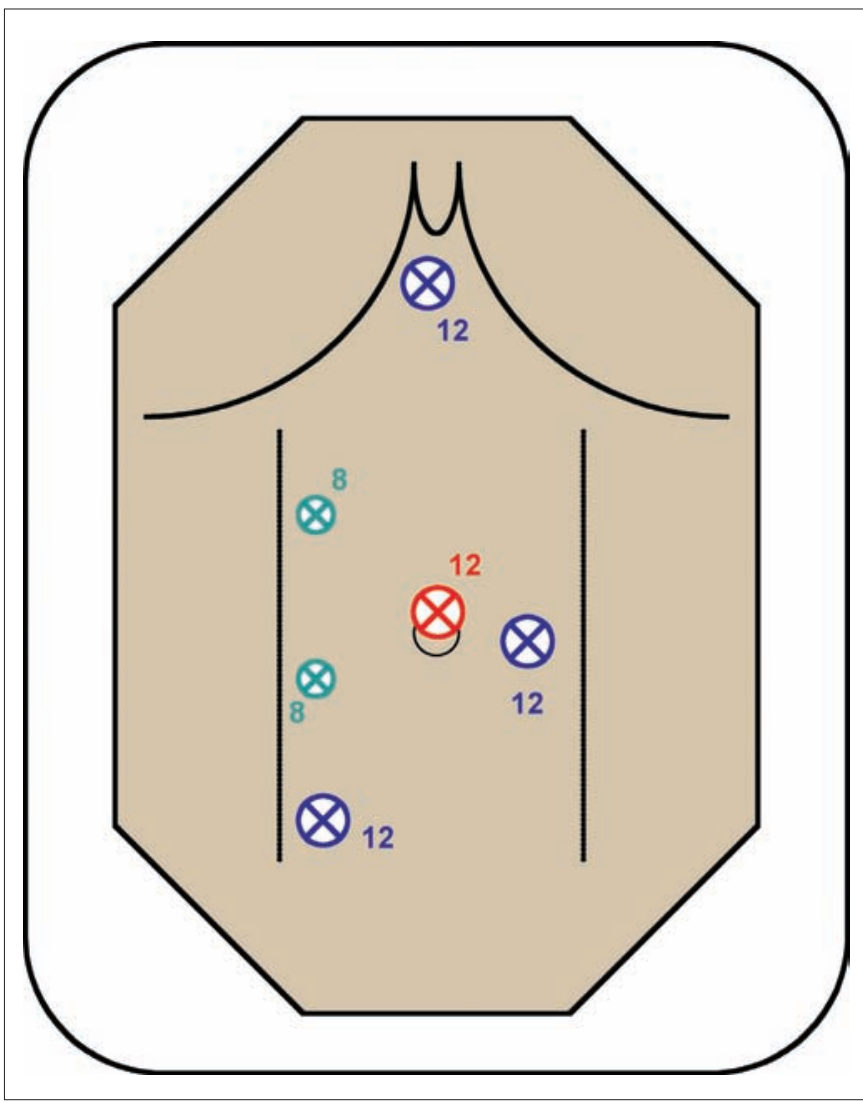

Fig. 1. Port placement for transperitoneal robot-assisted laparoscopic pyeloplasty, as commonly described in the literature. A 12-mm camera port is placed at the umbilicus. Two 8-mm robotic arm ports are then placed to create a triangle with the base facing laterally. A 12-mm assistant port can be placed as per surgeon preference - subxyphoid, just medial to the camera port, or caudally in the vicinity of the McBurney point. and proximal ureter is performed using standard laparoscopic techniques, reserving the robot for the ureteropelvic anastomosis. ${ }^{21,24-26,28}$ We routinely perform the entire procedure robotically as we believe that finer operative dissection can be obtained via robotic assistance.

Comparative studies between RALP and open or standard laparoscopic pyeloplasty are summarized in Table 2. Reported success rates vary from $86 \%$ to $100 \%$. In our series of 55 patients (54 with dismembered pyeloplasty; 1 with Y-V plasty), 95\% had clinical and scintigraphic resolution, with only 2 requiring successful secondary endopyelotomy. ${ }^{32}$ Thirty-one patients (56\%) were found to have a crossing vessel and 7 (13\%) had concomitant renal stone extraction. Mean operative time was less than 3 hours and anastomotic time 38 minutes, with a trend toward shorter times as the series matured. Mean length of hospital stay was 2.3 days with estimated blood loss of $55 \mathrm{~mL} /$ case. Based

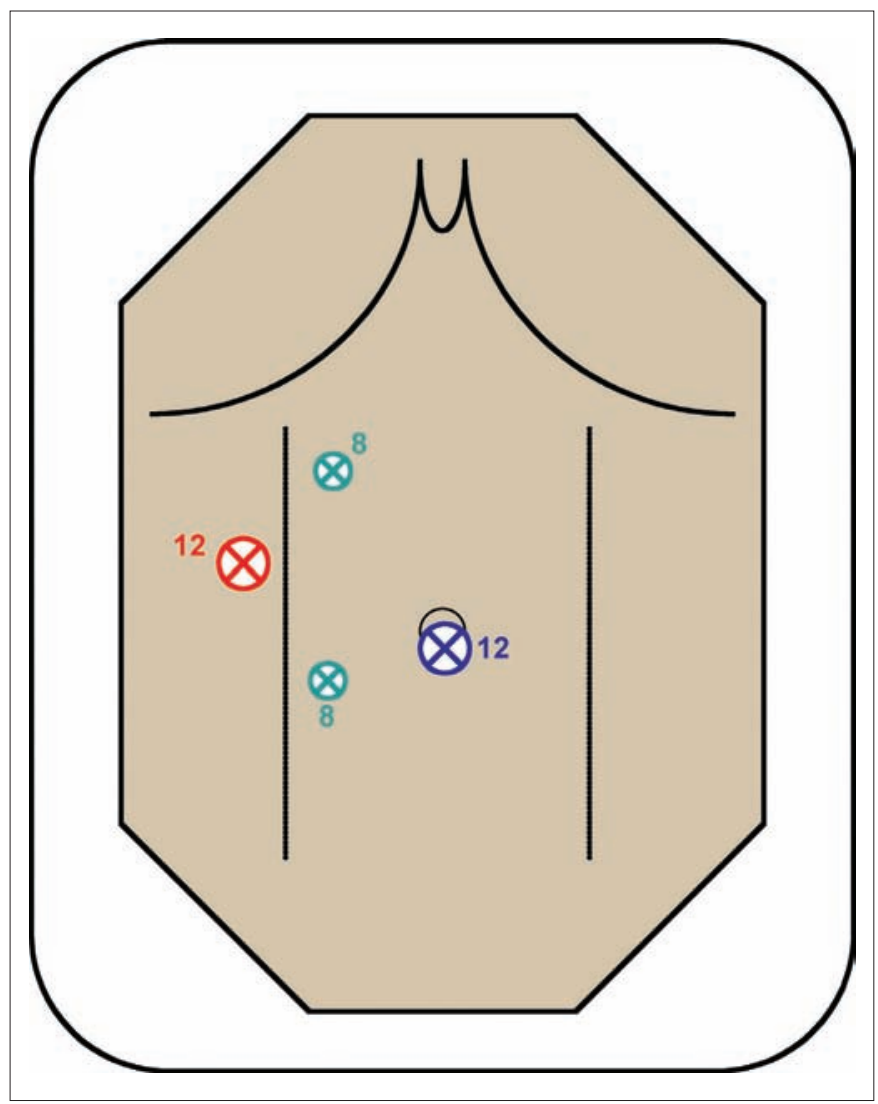

Fig. 2. Port placement for transperitoneal robot-assisted laparoscopic pyeloplasty as per the surgeon's preference. A 12-mm port is inserted at the umbilicus and pneumoperitoneum is established. This eventually serves as the assistant's port. By placing this port away from the robot, collisions are avoided. A second 12-mm camera port is placed along the anterior axillary line at the estimated location of the ureteropelvic junction. Lastly, 2 robotic arm ports are placed medial to the camera port to create an isoceles triangle with the base facing medially. 
on these data and other publications directly comparing RALP with open or standard laparoscopic pyeloplasty, the robotic approach appears safe and effective (Table 2 ). Intermediate-term results are slowly accumulating in the literature and compare favourably versus open pyeloplasty results. Unfortunately, as with other applications of robotassisted surgery, the biggest drawback and criticism centres on the purported lack of cost-effectiveness compared with other less expensive modalities. ${ }^{38,40-42}$ This is likely the single most important deterrent for wider application of RALP in publicly funded health care systems such as Canada's.

\section{Radical nephrectomy and nephrouterectomy}

Robot-assisted extirpative renal surgery has been described as a useful minimally invasive technique for both malignant and benign conditions. Numerous feasibility case series have been reported highlighting the safety and efficacy of

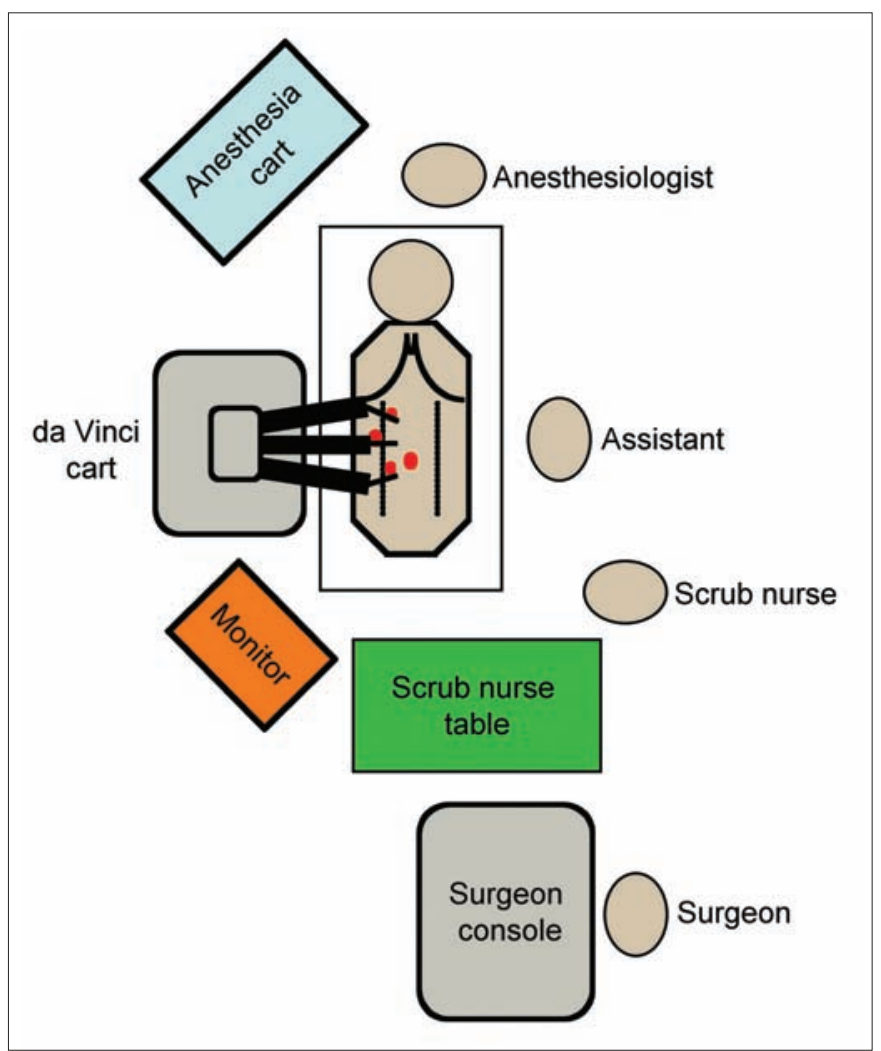

Fig. 3. Operating room set-up for robot-assisted surgery. The patient is placed in a $60^{\circ}$ lateral decubitus position. After port placement, the da Vinci system is docked in position posterior to the patient. The primary surgeon is seated at the remote surgical console. The surgical assistant is situated on the side across from the robot. A scrub nurse is near the foot of the bed. A monitor is positioned in view of the surgical assistant and scrub nurse. The anesthesiologist is at the head of the table. robotic assistance. ${ }^{43-48}$ No major patient or equipment complications were reported. Although a standard laparoscopic approach is usually employed for nephrectomy at most centres today, robot-assisted techniques are attractive to surgeons who have minimal laparoscopic experience. In contrast, most surgeons facile with basic laparoscopic skills have difficulty justifying the use of robotics for what is considered by many a relatively straightforward procedure. Most described techniques mirror the standard laparoscopic approach for renal dissection and extraction; however, the da Vinci system is not compatible with multifire clip appliers or standard endovascular stapling devices required for renovascular ligation and division. This has further discouraged routine use of robotic assistance in the extirpative kidney surgery setting.?

\section{Living-donor nephrectomy}

The most extensive experience with extirpative robotassisted renal surgery involves living-donor nephrectomy. Although some centres still consider open living-donor nephrectomy the "gold standard," 49 experience with laparoscopic donor nephrectomy, both purely laparoscopic and hand-assisted, continues to gain popularity. Advantages of a minimally invasive approach include reduced postoperative pain, shortened hospital stay and a quicker return to regular daily activities. ${ }^{50-52}$ Importantly, minimally invasive living-donor nephrectomy is also believed to have increased the donor pool by decreasing morbidity compared with open living-donor nephrectomy. ${ }^{53}$ However, the technically demanding nature of laparoscopic living-donor nephrectomy has made it an attractive candidate for robotic assistance. There is evidence that robot-assisted living-donor nephrectomy is safe and provides outcomes equivalent to both open and other minimally invasive techniques. ${ }^{54} \mathrm{~A}$ summary of published series of robot-assisted livingdonor nephrectomy is shown in Table 3. It should be acknowledged that the impressive mean operative times (range 143-185 $\mathrm{min}$ ) reported by each group did not include operating room set-up and docking of the da Vinci system before dissection. Taken together, the superiority of robotassisted donor nephrectomy over standard techniques has yet to be proven.

\section{Partial nephrectomy}

In contemporary times whereby most renal tumours are discovered incidentally via abdominal imaging for an unrelated indication, ${ }^{58}$ these tumours are frequently amenable to nephron-sparing extirpative techniques. Patients with exophytic lesions less than $4 \mathrm{~cm}$ are ideal candidates for partial 


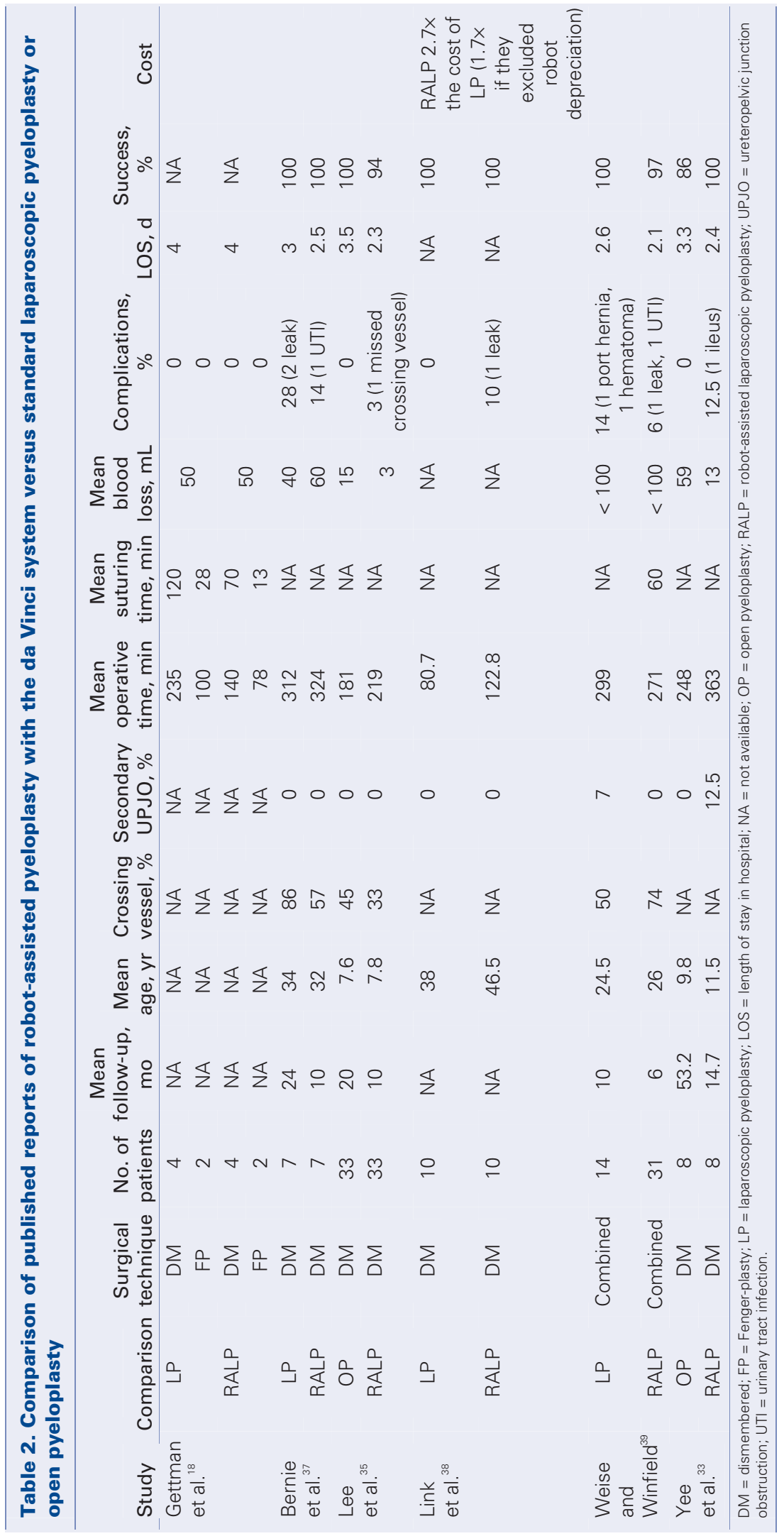

nephrectomy in the elective setting. ${ }^{59}$ These techniques are further justified in patients with baseline compromised renal function, the potential for future renal deterioration or solitary kidney conditions. ${ }^{60,61}$ In recent years, there has been an explosion of reports describing minimally invasive laparoscopic techniques for partial nephrectomy, including robot-assisted techniques. ${ }^{62-66}$ Pure laparoscopic partial nephrectomy is technically challenging, and strategies to simplify resection and reconstruction while minimizing ischemic time have been sought. Theoretically, the enhanced ability to adjust resection angles, and the ability to facilitate intracorporal suturing with the EndoWrist Instruments have made robot-assisted laparoscopic partial nephrectomy (RALPN) an especially attractive alternative. A summary of published RALPN studies is shown in Table 4. Represented are 5 case series and a single case report. Furthermore, conversion rates of $25 \%$ and $20 \%$ in the reports by Phillips and colleagues ${ }^{69}$ and Caruso and colleagues ${ }^{70}$ highlight the steep early learning curve with this procedure. More convincing studies demonstrating the superiority of RALPN over conventional laparoscopic techniques are needed before RALPN can be adopted routinely.

\section{Renovascular and adrenal surgery}

There are numerous case reports and a few case series in the literature describing novel and innovative applications of surgical robots. A few examples of these applications have been described specifically pertaining to renal surgery. Our group ${ }^{73}$ described a technique of robot-assisted renal artery aneurysm resection and reconstruction using the da Vinci sytem. With its ability to facilitate precise dissection and fine suturing, the robot provided an excellent vehicle in which a 10-minute anastomosis was accomplished (Fig. 4). Accordingly, other procedures requiring renovascular reconstruction can be facilitated using the robot. Although not yet performed laparoscopically, Hoznek and coauthors $^{74}$ described renal transplantation with all vascular anastomoses performed by 
the robot. Our group continues to assess techniques for allograft positioning through a small incision in order to facilitate laparoscopic robot-assisted renal transplantation.

Since the first laparoscopic adrenalectomy by Gagner and colleagues in $1992,{ }^{75,76}$ a paradigm shift has taken place in favour of the laparoscopic approach versus the previous standard open technique. Shorter hospital stays, reduced pain scores and improved convalescence have consistently been reported. ${ }^{77-81}$ The experience with robot-assisted adrenalectomy is not nearly as robust. Once again, however, it has been shown that robot-assisted laparoscopic adrenalectomy can be performed safely through adoption of established laparoscopic techniques. ${ }^{82-89}$ The worldwide, and certainly Canadian, role of robot-assistance in all of these procedures has yet to be born out. Because of the current economic climate and structure of the Canadian health care system, use of the surgical robot for adrenalectomy will likely be limited.

\section{The future}

Robotic surgery is still in its infancy. The fields of urology, cardiac surgery, neurosurgery, orthopedics and fetal surgery have appropriately embraced the technology with the ambition of advancing medical frontiers and application. The goal of applied surgical robotics is improved patient care. Through active clinical and laboratory experimentation, applications specific to robotic renal surgery will likely advance in parallel to other disciplines. Currently, developments in surgical robotic technology evolves around improved visualization technology, enhanced real-time imaging, ${ }^{90}$ and robotic-enhanced haptic and temperature sensors. ${ }^{91}$ Furthermore, robotic ultrasonography and acoustic holography may soon provide real-time imaging that can define abnormal tissues intraoperatively. One of the most promising future applications of this technology involves remote telesurgery. Our group has recently described the use of an internet protocol virtual private network and satellite links to ascertain the feasibility of long-distance surgery using both the Zeus and da Vinci robotic platforms ${ }^{92,93}$ Results of porcine RALPs indicated that proficient complex reconstructions can be achieved despite significant network latency and occasional jitter. As the technology evolves, the clinical implications of remote telesurgery will become tangible.

The interest in acquiring robotic skills among surgeons is rapidly increasing. In a survey of American and Canadian

Table 3. A summary of published surgical series on robot-assisted living-donor nephrectomy

\begin{tabular}{|c|c|c|c|c|c|}
\hline Study $(n)$ & $\begin{array}{l}\text { Mean operative } \\
\text { time, } \min \end{array}$ & $\begin{array}{l}\text { Mean } \\
\text { WIT, s }\end{array}$ & Mean LOS, d & Allograft outcome & Complications \\
\hline Horgan et al. ${ }^{55}(12)$ & 166 & 79 & 1.9 & No DGF & $\begin{array}{l}\text { Clostridium difficile colitis in } 1 \text { patient; } \\
\text { wound infection in } 1 \text { patient }\end{array}$ \\
\hline Talamini et al. ${ }^{56}(15)$ & 143 & - & 1.0 & NA & None \\
\hline Renoult et al. ${ }^{54}(13)$ & 185 & 430 & 5.8 & $\begin{array}{c}\text { POD } 5 \\
\text { Mean } \mathrm{CICr}=62 \mathrm{~mL} / \mathrm{min}\end{array}$ & DVT in 1 patient \\
\hline Horgan et al..$^{57}(273)$ & 150 & 98 & 2.3 & $\begin{array}{c}\text { Mean } \mathrm{Cr}=1.4 \mathrm{mg} / \mathrm{dL} \text { at } \\
6 \mathrm{mo}\end{array}$ & $\begin{array}{l}\text { Overall } 9 \text { "major"; } \\
1 \text { death unrelated to operation }\end{array}$ \\
\hline
\end{tabular}

Table 4. Summary of published reports of robot-assisted laparoscopic partial nephrectomy with the da Vinci system

\begin{tabular}{|c|c|c|c|c|c|c|}
\hline Study $(n)$ & $\begin{array}{l}\text { Mean lesion } \\
\text { size, } \mathrm{cm}\end{array}$ & $\begin{array}{c}\text { Mean operative } \\
\text { time, min }\end{array}$ & $\begin{array}{c}\text { Mean hilar } \\
\text { clamp time, min }\end{array}$ & $\mathrm{EBL}, \mathrm{mL}$ & Mean LOS, d & Complications \\
\hline Gettman et al. ${ }^{67}$ (13) & 3.5 & 215 & 22 & 170 & 4.3 & 1 postoperative ileus \\
\hline Stifelman et al. ${ }^{68}(1)$ & 2.0 & 230 & 32 & 150 & 2.0 & None \\
\hline Phillips et al. ${ }^{69}(12)$ & 1.8 & 265 & 26 & 240 & 2.7 & $\begin{array}{c}2 \text { open conversions for bleeding; } \\
1 \text { conversion for robot malfunction; } \\
1 \text { postoperative urine leak }\end{array}$ \\
\hline Caruso et al. $^{70}(10)$ & 1.9 & 279 & 26 & 240 & 2.6 & $\begin{array}{c}2 \text { conversions for bleeding, poor } \\
\text { visualization; } 1 \text { postoperative urinary } \\
\text { retention }\end{array}$ \\
\hline Kaul et al. ${ }^{71}(10)$ & 2.0 & 158 & 21 & 92 & 1.5 & None \\
\hline Rogers et al. $^{72}(14)$ & 3.6 & 192 & 31 & 230 & 2.6 & None; "complex" lesions \\
\hline
\end{tabular}


urology residents on laparoscopic and robotic surgery, 54\% of respondents reported that robotic surgery was being performed at their centre. Twenty-two percent of resident respondents had been trained in robotic surgery and 34\% anticipated performing robotic surgery on completion of residency. In contrast, results of a similar survey of residents and practising urologists published just 2 years earlier did not even address the topic of robotic surgery. ${ }^{94}$ This observation highlights the rapid evolution of robotics in contemporary times.

Lastly, any Canadian review of robotics in urology would be incomplete without addressing the potential economic strain this technology may pose on our publicly funded system. Most analyses of cost-effectiveness in the literature have focused on the US hospital-based model whereby the da Vinci system is used for multiple procedures by multiple disciplines. Cost-analyses from a urological perspective have focused exclusively on the robot-assisted laparoscopic prostatectomy model. ${ }^{95-100}$ However, some extrapolations are still possible. When Computer Motion, Inc., initially merged with Intuitive Surgical, Inc., in 2003, the cost of the da Vinci system was slightly higher than US\$1000 000. The newer da Vinci S system, complete with new 3-dimensional highdefintion visual technology, a 20\%-30\% wider field of view, multiple video displays, slimmer telescoping instrument arms and more user-friendly setup apparatus, has a price tag closer to US\$1 500 000. An additional fourth arm (not usually necessary for most renal-related procedures) can be purchased for an additional US\$175 000. Annual maintenance contracts are usually about US\$100 000, and costs for nonreusable equipment range from US $\$ 700$ to $\$ 1200$ per case, depending on the procedure, number of ports and accessory instrument use. Interestingly, a 2007 analysis of

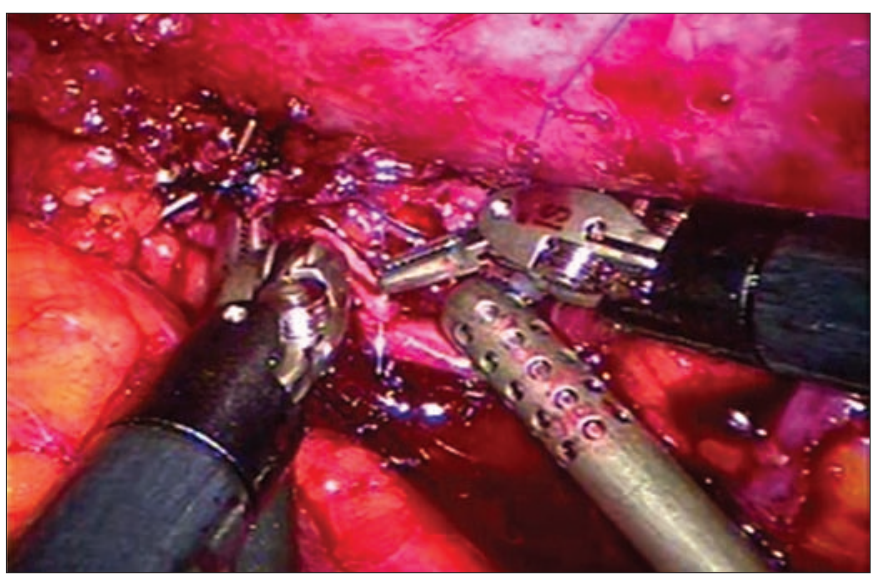

Fig. 4. Laparoscopic view of robot-assisted renal artery reconstruction after resection of $2.5-\mathrm{cm}$ left renal artery aneursym. The relative ease of intracorporal suturing afforded by the da Vinci robot enabled a minimally invasive approach. initiating a robotic prostatectomy program in a publicly funded system in Spain concluded that it was neither costeffective nor worthwhile, citing the large upfront cost of the da Vinci system and the monopoly that a single company has on the surgical robotics industry as the main deterrent. ${ }^{101}$ And although no formal economic analysis has been published in the Canadian system specifically addressing robot-assisted renal surgery, the technology is inarguably expensive. For each of the procedures described above, feasibility has been proven, but necessity is still debated. In contrast, robot-assisted laparoscopic radical prostatectomy is now considered by many to be one of the standards of care in the United States, and the technique is gaining popularity as experience grows here in Canada.

\section{Conclusion}

Pertaining to renal applications, a niche for robot-assisted pyeloplasty and partial nephrectomy continues to be carved out, while interest in radical extirpative renal surgery has waned in recent years. Nevertheless, through continued technological advancement, education and commercial competition, further surgical robotic application will develop and hopefully become accessible to practising urologists and their patients in the very near future.

From the *Department of Surgery, Division of Urology, University of Western Ontario, $†$ Schulich School of Medicine, University of Western Ontario, London, Ont., and the †Department of Surgery, Division of Urology, Laval University, Québec City, Que.

This article has been peer reviewed.

Competing interests: None declared.

\section{References}

1. Kwoh YS, Hou J, Jonckheere EA, et al. A robot with improved absolute positioning accuracy for CT guided stereotactic brain surgery. IEEE Trans Biomed Eng 1988;35:153-60.

2. Davies BL, Hibberd RD, Ng WS, et al. The development of a surgeon robot for prostatectomies. Proc Inst Mech Eng [H] 1991;205:35-8.

3. Miyake 0 , Kiuchi H, Yoshimura K, et al. Urological robotic surgery: preliminary experience with the Zeus system. Int J Urol 2005;12:928-32.

4. Eichel L. Robotics in urologic surgery: risks and benefits. AUA Update Series 2005;24:106.

5. Nguan C, Kwan K, Al Omar M, et al. Robotic pyeloplasty: experience with three robotic plafforms. Can J Urol 2007;14:3571-6.

6. Nguan C, Girvan A, Luke PP. Robotic surgery vs. laparoscopy: a comparison between two robotic systems and laparoscopy. J Robot Surg 2008;1:263-8.

7. Kaul S, Menon M. Robotics in laparoscopic urology. Minim Invasive Ther Allied Technol 2005; 14:62-70.

8. Hoznek A, Hubert J, Antiphon P, et al. Robotic renal surgery. Urol Clin North Am 2004;31:731-6.

9. Tan BJ, Smith AD. Ureteropelvic junction obstruction repair: When, how, what? Curr Opin Urol 2004; 14:55-9.

10. O'Reilly PH, Brooman PJ, Mak S, et al. The long-term results of Anderson-Hynes pyeloplasty. BJU Int 2001;87:287-9

11. Schuessler WW, Grune MT, Tecuanhuey LV, et al. Laparoscopic dismembered pyeloplasty. J Urol 1993; 150:1795-9.

12. Zhang $\mathrm{X}$, Li HZ, Ma X, et al. Retrospective comparison of retroperitoneal laparoscopic versus open 
dismembered pyeloplasty for ureteropelvic junction obstruction. J Urol 2006; 176:1077-80.

13. Winfield HN. Management of adult ureteropelvic junction obstruction - Is it time for a new gold standard? J Urol 2006;176:866-7.

14. Inagaki T, Rha KH, Ong AM, et al. Laparoscopic pyeloplasty: current status. BJU Int 2005;95 (Suppl 2): 102-5.

15. Munver R, Sosa RE, del Pizzo JJ. Laparoscopic pyeloplasty: history, evolution, and future. J Endourol 2004; 18:748-55

16. Jarrett TW, Chan DY, Charambura TC, et al. Laparoscopic pyeloplasty: the first 100 cases. J Urol 2002;167:1253-6

17. Janetschek G, Peschel R, Frauscher F. Laparoscopic pyeloplasty. Urol Clin North Am 2000;27:695-704.

18. Gettman MT, Peschel R, Neururer R, et al. A comparison of laparoscopic pyeloplasty performed with the daVinci robotic system versus standard laparoscopic techniques: initial clinical results. Eur Urol 2002; 42:453-7.

19. Gettman MT, Neururer R, Bartsch G, et al. Anderson-Hynes dismembered pyeloplasty performed using the da Vinci robotic system. Urology 2002;60:509-13.

20. Bentas W, Wolfram M, Brautigam R, et al. Da Vinci robot assisted Anderson-Hynes dismembered pyeloplasty: technique and 1 year follow-up. World I Urol 2003;21:133-8.

21. Yohannes P, Burionrappa SC. Rapid communication: laparoscopic Anderson-Hynes dismembered pyeloplasty using the da Vinci robot: technical considerations. J Endourol 2003;17:79-83.

22. Peschel R, Neururer R, Bartsch G, et al. Robotic pyeloplasty: technique and results. Urol Clin North Am 2004;31:737-41.

23. Atug F, Castle EP, Burgess SV, et al. Concomitant management of renal calculi and pelvi-ureteric junction obstruction with robotic laparoscopic surgery. BJU Int 2005;96:1365-8.

24. Atug F, Woods M, Burgess SV, et al. Robotic assisted laparoscopic pyeloplasty in children. J Urol 2005:174:1440-2.

25. Mendez-Torres F, Woods M, Thomas R. Technical modifications for robot-assisted laparoscopic pyeloplasty. J Endourol 2005; 19:393-6.

26. Palese MA, Munver R, Phillips CK, et al. Robot-assisted laparoscopic dismembered pyeloplasty. JSLS 2005; $9: 252-7$

27. Patel V. Robotic-assisted laparoscopic dismembered pyeloplasty. Urology 2005;66:45-9.

28. Siddiq FM, Leveillee RJ, Villicana P, et al. Computer-assisted laparoscopic pyeloplasty: University of Miami experience with the daVinci Surgical System. J Endourol 2005; 19:387-92.

29. Atug F, Burgess SV, Castle EP, et al. Role of robotics in the management of secondary ureteropelvic junction obstruction. Int J Clin Pract 2006;60:9-11.

30. Kutikov A, Nguyen M, Guzzo T, et al. Robot assisted pyeloplasty in the infant — lessons learned. J Urol 2006; 176:2237-9

31. Schwentner C, Pelzer A, Neururer R, et al. Robotic Anderson-Hynes pyeloplasty: 5-year experience of one centre. BJU Int 2007; 100:880-5.

32. Erdeljan P, Caumartin Y, Warren J, et al. Robotic pyeloplasty: long-term follow-up of first Canadian experience. Can Urol Assoc J 2008;2:309.

33. Yee DS, Shanberg AM, Duel BP, et al. Initial comparison of robotic-assisted laparoscopic versus open pyeloplasty in children. Urology 2006;67:599-602.

34. Chammas M Jr, Feuillu B, Coissard A, et al. Laparoscopic robotic-assisted management of pelvi-ureteric junction obstruction in patients with horseshoe kidneys: technique and 1-year follow-up. BJU Int 2006:97:579-83

35. Lee RS, Retik AB, Borer IG, et al. Pediatric robot assisted laparoscopic dismembered pyeloplasty: comparison with a cohort of open surgery. J Urol 2006;175:683-7.

36. Klingler HC, Remzi M, Janetschek G, et al. Comparison of open versus laparoscopic pyeloplasty techniques in treatment of uretero-pelvic junction obstruction. Eur Urol 2003;44:340-5.

37. Bernie JE, Venkatesh R, Brown J, et al. Comparison of laparoscopic pyeloplasty with and without robotic assistance. JSLS 2005;9:258-61.

38. Link RE, Bhayani SB, Kavoussi LR. A prospective comparison of robotic and laparoscopic pyeloplasty. Ann Surg 2006;243:486-91.

39. Weise ES, Winfield HN. Robotic computer-assisted pyeloplasty versus conventional laparoscopic pyeloplasty. J Endourol 2006:20:813-9.

40. Eden CG. Minimally invasive treatment of ureteropelvic junction obstruction: a critical analysis of results. Eur Urol 2007;52:983-9.

41. Badwan K, Bhayani S. Robotic pyeloplasty: a critical appraisal. Int J Med Robot 2007;3:20-2.

42. Bhayani SB, Link RE, Varkarakis JM, et al. Complete daVinci versus laparoscopic pyeloplasty: cost analysis. J Endourol 2005: 19:327-32.

43. Gill IS, Sung GT, Hsu TH, et al. Robotic remote laparoscopic nephrectomy and adrenalectomy: the initial experience. J Urol 2000;164:2082-5.

44. Guillonneau B, Jayet C, Tewari A, et al. Robot assisted laparoscopic nephrectomy. J Urol 2001; 166:200-1

45. Storm D, Fulmer B, Danella J, et al. Robotic-assisted laparoscopic nephrectomy: experience with 100 cases. J Urol 2007;177:234.

46. Finley DS, Melamud 0, Ornstein DK. Combined robot-assisted laparoscopic nephroureterectomy and radical prostatectomy. J Endourol 2007;21:411-4.

47. Nanigian DK, Smith W, Ellison LM. Robot-assisted laparoscopic nephroureterectomy. J Endourol 2006;20:463-5, discussion 465-6.

48. Rose K, Khan S, Godbole H, et al. Robotic assisted retroperitoneoscopic nephroureterectomy - first experience and the hybrid port technique. Int I Clin Pract 2006;60:12-4

49. Najarian JS, Chavers BM, Mchugh LE, et al. 20 years or more of follow-up of living kidney donors. Lancet 1992;340:807-10.

50. Tooher RL, Rao MM, Scott DF, et al. A systematic review of laparoscopic live-donor nephrectomy. Transplantation 2004;78:404-14.

51. Novotny MJ. Laparoscopic live donor nephrectomy. Urol Clin North Am 2001;28:127-35.

52. Leventhal JR, Deeik RK, Joehl RJ, et al. Laparoscopic live donor nephrectomy — Is it safe? Transplantation 2000;70:602-6.

53. Lee BR, Chow GK, Ratner LE, et al. Laparoscopic live donor nephrectomy: outcomes equivalent to open surgery. J Endourol 2000;14:811-9, discussion 819-20.

54. Renoult E, Hubert J, Ladriere M, et al. Robot-assisted laparoscopic and open live-donor nephrectomy: a comparison of donor morbidity and early renal allograft outcomes. Nephrol Dial Transplant 2006;21:472-7.

55. Horgan S, Vanuno D, Sileri P, et al. Robotic-assisted laparoscopic donor nephrectomy for kidney transplantation. Transplantation 2002;73:1474-9.

56. Talamini MA, Chapman S, Horgan S, et al. A prospective analysis of 211 robotic-assisted surgical procedures. Surg Endosc 2003;17:1521-4.

57. Horgan S, Galvani C, Gorodner MV, et al. Effect of robotic assistance on the "learning curve" for laparoscopic hand-assisted donor nephrectomy. Surg Endosc 2007;21:1512-7.

58. Pantuck AJ, Zisman A, Rauch MK, et al. Incidental renal tumors. Urology 2000;56:190-6.

59. Herr HW. Partial nephrectomy for unilateral renal carcinoma and a normal contralateral kidney: 10-year followup. J Urol 1999;161:33-4.

60. Lau WK, Blute ML, Weaver AL, et al. Matched comparison of radical nephrectomy vs nephron-sparing surgery in patients with unilateral renal cell carcinoma and a normal contralateral kidney. Mayo Clin Proc 2000;75:1236-42.

61. Fergany AF, Hafez KS, Novick AC. Long-term results of nephron sparing surgery for localized renal cell carcinoma: 10-year followup. J Urol 2000;163:442-5.

62. Beasley KA, Al Omar M, Shaikh A, et al. Laparoscopic versus open partial nephrectomy. Urology 2004;64:458-61.

63. Simon SD, Ferrigni RG, Novicki DE, et al. Mayo Clinic Scottsdale experience with laparoscopic nephron sparing surgery for renal tumors. J Urol 2003;169:2059-62.

64. Ogan K, Cadeddu JA. Minimally invasive management of the small renal tumor: review of laparoscopic partial nephrectomy and ablative techniques. J Endourol 2002;16:635-43.

65. Haber GP, Gill IS. Laparoscopic partial nephrectomy: contemporary technique and outcomes. Eur Urol 2006:49:660-5.

66. Guillonneau B, Bermudez H, Gholami S, et al. Laparoscopic partial nephrectomy for renal tumor: single center experience comparing clamping and no clamping techniques of the renal vasculature. J Urol 2003:169:483-6

67. Gettman MT, Blute ML, Chow GK, et al. Robotic-assisted laparoscopic partial nephrectomy: technique and initial clinical experience with DaVinci robotic system. Urology 2004;64:914-8.

68. Stifelman MD, Caruso RP, Nieder AM, et al. Robot-assisted laparoscopic partial nephrectomy. ISLS 2005;9:83-6.

69. Phillips CK, Taneja SS, Stifelman MD. Robot-assisted laparoscopic partial nephrectomy: the NYU technique. J Endourol 2005;19:441-5.

70. Caruso RP, Phillips CK, Kau E, et al. Robot assisted laparoscopic partial nephrectomy: initial experience. J Urol 2006:176:36-9.

71. Kaul S, Laungani R, Sarle R, et al. da Vinci assisted robotic partial nephrectomy: technique and results at a mean of 15 months of follow-up. Eur Urol 2007:51:186-91.

72. Rogers CG, Singh A, Blatt AM, et al. Robotic partial nephrectomy for complex renal tumors: surgical technique. Eur Urol 2008;53:514-21.

73. Luke P, Knudsen BE, Nguan CY, et al. Robot-assisted laparoscopic renal artery aneurysm reconstruction. J Vasc Surg 2006:44:651-3. 
74. Hoznek A, Zaki SK, Samadi DB, et al. Robotic assisted kidney transplantation: an initial experience. J Urol 2002;167:1604-6.

75. Gagner M, Lacroix A, Prinz RA, et al. Early experience with laparoscopic approach for adrenalectomy. Surgery 1993; 114:1120-4.

76. Gagner M, Lacroix A, Bolte E. Laparoscopic adrenalectomy in Cushing's syndrome and pheochromocytoma. N Engl J Med 1992;327:1033

77. Thompson $\mathrm{GB}$, Grant $\mathrm{CS}$, van Heerden JA, et al. Laparoscopic versus open posterior adrenalectomy: a case-control study of 100 patients. Surgery 1997;122:1132-6.

78. Stanford A, Upperman IS, Nguyen N, et al. Surgical management of open versus laparoscopic adrenalectomy: outcome analysis. J Pediatr Surg 2002;37:1027-9.

79. Schell SR, Talamini MA, Udelsman R. Laparoscopic adrenalectomy for nonmalignant disease: improved safety, morbidity, and cost-effectiveness. Surg Endosc 1999;13:30-4.

80. Janetschek G. Surgical options in adrenalectomy: laparoscopic versus open surgery. Curr Opin Urol 1999; 9:213-8.

81. Brunt $L M$. The positive impact of laparoscopic adrenalectomy on complications of adrenal surgery. Surg Endosc 2002; 16:252-7.

82. Julien JS, Ball D, Schulick R. Robot-assisted cortical-sparing adrenalectomy in a patient with von hippel-lindau disease and bilateral pheochromocytomas separated by 9 years. J Laparoendosc Adv Surg Tech A 2006;16:473-7.

83. Winter JM, Talamini MA, Stanfield CL, et al. Thirty robotic adrenalectomies: a single institution's experience. Surg Endosc 2006;20:119-24.

84. Morino $M$, Beninca $G$, Giraudo $G$, et al. Robot-assisted vs laparoscopic adrenalectomy: a prospective randomized controlled trial. Surg Endosc 2004;18:1742-6.

85. Brunaud L, Bresler L, Ayav A, et al. Advantages of using robotic Da Vinci system for unilateral adrenalectomy: early results [article in French]. Ann Chir 2003;128:530-5.

86. D'Annibale A, Fiscon V, Trevisan $P$, et al. The da Vinci robot in right adrenalectomy: considerations on technique. Surg Laparosc Endosc Percutan Tech 2004;14:38-41.

87. Desai MM, Gill IS, Kaouk JH, et al. Robotic-assisted laparoscopic adrenalectomy. Urology 2002; 60:1104-7.

88. Bentas W, Wolfram M, Brautigam R, et al. Laparoscopic transperitoneal adrenalectomy using a remotecontrolled robotic surgical system. J Endourol 2002;16:373-6.
89. Young JA, Chapman WH III, Kim VB, et al. Robotic-assisted adrenalectomy for adrenal incidentaloma: case and review of the technique. Surg Laparosc Endosc Percutan Tech 2002;12:126-30.

90. Cleary K, Nguyen C. State of the art in surgical robotics: clinical applications and technology challenges. Comput Aided Surg 2001;6:312-28.

91. Pandya A, Auner G. Robotics technology: a journey into the future. Urol Clin North Am 2004;31:793$800, x$.

92. Nguan CY, Morady R, Wang C. Robotic pyeloplasty using internet protocol and satellite network-base telesurgery. Int J Med Robot 2008;4:10-4.

93. Nguan CY, Miller B, Patel R. Pre-clinical remote telesurgery trial of a da Vinci telesurgery prototype. Int J Med Robot 2008;4:304-9.

94. Wang DS, Winfield HN. Survey of urological laparoscopic practice patterns in the midwest. J Urol 2004; 172:2282-6.

95. Lotan Y, Caduddu JA, Gettman MT. The new economics of radical prostatectomy: cost comparison of open, laparoscopic and robot assisted techniques. J Urol 2004;172:1431-5.

96. Mouraviev V, Nosnik I, Sun L, et al. Financial comparative analysis of minimally invasive surgery to open surgery for localized prostate cancer: a single-institution experience. Urology 2007;69:311-4.

97. Scales CD Jr, Jones PJ, Eisenstein EL, et al. Local cost structures and the economics of robot assisted radical prostatectomy. J Urol 2005; 174:2323-9.

98. Burgess SV, Atug F, Castle EP, et al. Cost analysis of radical retropubic, perineal, and robotic prostatectomy. J Endourol 2006;20:827-30.

99. Hegarty NJ, Kaouk JH. Radical prostatectomy: a comparison of open, laparoscopic and robot-assisted laparoscopic techniques. Can I Urol 2006; (Suppl 1):56-61.

100. Steinberg PL, Merguerian PA, et al. The cost of learning robotic-assisted prostatectomy. Urology 2008; 72:1068-72.

101. Martínez-Salamanca Il, Allona Almagro A. technical and economic reasons for the implantation of robotic surgery in a public health system (Spanish model) [article in Spanish]. Actas Urol Esp 2007;31:603-10.

Correspondence: Dr. Patrick Luke, London Health Sciences Centre, University Campus, 339 Windermere Rd., London ON N6A 5A5; fax 519 663-3858; patrick.luke@lhsc.on.ca 